\title{
A study of cerebral blood flow and metabolism in epileptic psychosis using positron emission tomography and oxygen
}

\author{
B GALLHOFER, ${ }^{*}$ MR TRIMBLE, ${ }^{*}$ R FRACKOWIAK,${ }^{*} \dagger$ J GIBBS,$\dagger$ T JONES $\dagger$ \\ From the National Hospital for Nervous Disease, ${ }^{*}$ Queen Square, and the MRC Cyclotron Unit, \\ †Hammersmith Hospital, London, UK
}

SUMMARY Data are presented on four groups using positron tomography and $15 \mathrm{O}$ inhalation. Compared to age-matched volunteer controls, epileptic patients show regions of low blood flow and hypometabolism as found in previous studies. Epileptic psychotic and non-psychotic patients have been compared, and the main differences noted were lower rOER in the psychotic group, especially in frontal, temporal and basal ganglia regions. When a group of psychotic patients receiving neuroleptic drugs was compared to those free of these medications the rOER was higher in the treated sample, and the rCBF fell, significantly in some areas. These data are discussed in the light of other reports of positron tomography in psychosis.

The relationship between epilepsy and psychosis has been recognised for well over a century, but has received increasing attention since the reports from Pond, ${ }^{1}$ Hill, ${ }^{2}$ and Slater and Beard. ${ }^{3}$ These authors suggested that an increased association between epilepsy and psychosis occurred, and drew attention to the often paranoid presentation of the psychosis, noting a link of the latter to temporal lobe pathology. In more recent work, in which the Present State Examination (PSE) of Wing has been used to evaluate more precisely the phenomenological presentation of this psychosis, Perez and Trimble ${ }^{4}$ have noted the strong association between presentation with a pattern of nuclear schizophrenia, based on Schneiderian first rank symptoms, and epilepsy with complex partial seizures. Another link in this field was the suggestion by Flor Henry ${ }^{5}$ that the presentation of the psychosis in temporal lobe epilepsy was interlinked with the laterality of the focus. He thus suggested that a schizophreniform disorder was more likely to be related to a left sided lesion, and a manic depressive illness to a right sided one. Although work carried out at the National Hospitals ${ }^{6}$ has been able to confirm a link between the left side and a schizophreniform presentation, several authors have failed in this endeavour. Thus Slater and Beard ${ }^{3}$ did not specifically comment on a lateral-

Address for reprint requests: Dr MR Trimble, National Hospital for Nervous Diseases, Queen Square, London, WC1N 3BG, UK.

Received 2 July 1984. Accepted 18 August 1984 ity effect, and more recently the extensive series of Kristensen and Sindrup, ${ }^{7}$ in which 96 patients with epilepsy and psychosis were compared to epileptic non-psychotic controls, no laterality bias was detected.

Many of the above quoted studies have assessed the side of the epileptic lesion using electroencephalographic techniques. More recently Toone and Driver $^{8}$ examined retrospectively the side of pathology in a series of patients with epilepsy and psychosis whose clinical presentation was rated with the Syndrome Check List, derived from the Present State Examination and adapted for retrospective case history evaluation. All patients had computed tomography (CT) carried out and, when combined schizophrenic and paranoid groupings were analysed together, there was a trend towards left sided abnormalities in this group. Their conclusion, however, was that structural damage, and the laterality of it, probably played a minor role in determining the pattern of psychotic illness in epilepsy.

Flor Henry, ${ }^{5}$ in his discussion of the pathogenesis of epileptic psychosis, suggested epileptic factors rather than structural factors were of importance, in keeping with the results described by Toone and Driver. ${ }^{8}$ The recently described positron emission tomography technique is one method for further examining the relationship between functional disturbance of the brain and the development of epileptic psychosis. The Hammersmith Hospital has developed the technique of quantitative assessment 
of both the regional cerebral blood flow (rCBF) and the regional oxygen metabolism (rCMRO2), and the regional oxygen extraction ratio (rOER) being defined as the relationship between blood flow and oxygen utilisation. ${ }^{9}$ In a recent report ${ }^{10}$ we have described an interictal study on patients with partial epilepsy using this technique and noted abnormal values, particularly with regard to the $\mathrm{rCMRO} 2$ and rCBF in patients with complex partial seizures. In this report we present interictal data on patients with epilepsy, a group of which have epileptic psychosis. The intention of the study was to test hypotheses with regard to differences between groups of patients with epilepsy who were psychotic and others who were not, and the effects of neuroleptic medication on the rCBF, rCMRO2 and rOER.

\section{Materials and methods}

Four groups of patients have been examined, two of which were psychotic. The first of the latter comprised six patients who were free from neuroleptic medication at the time of performing the scan. One patient was drug-free for nine days, a second for twenty four days, two others had no neuroleptic medication for over seven months, and two had never received this kind of treatment. The second group $(\mathrm{N}=6)$ were receiving antipsychotic medication at the time of the scan. Three from this group were scanned on two occasions, on one occasion being drug-free, and on another while receiving neuroleptics. The two other groups examined included an age-matched, non-psychotic epileptic sample $(\mathbf{N}=5)$, and an age-matched non-epileptic volunteer control group $(\mathrm{N}=5)$. The epileptic samples were receiving similar anticonvulsant prescriptions and had partial seizures.

The psychosis of all patients was rated, with one exception, with the PSE, the examination occurring as close as possible to the time of the scan.

The technique of scanning has been fully outlined elsewhere ${ }^{10}$ and will not be presented here. In the majority of patients and controls, planes were scanned at $\mathrm{OM}+2,+4$, +6 , and $+8 \mathrm{cms}$, and all were corrected for attenuation by the corresponding transmission scans. Tracer equations which relate steady state measurements to tissue blood flow, and oxygen extraction ratios, were used to calculate absolute quantitative values of rCBF, rOER, and rCMRO2.

A computer printout of the quantitative data was available, and $2.5 \mathrm{~cm}^{2}$ regions of interest (RO1) were chosen, corresponding to the frontal and occipital regions on slices at $\mathrm{OM}+4$ and $\mathrm{OM}+6$ respectively. Three areas were measured from the temporal cortex, each of $1.5 \mathrm{~cm}^{2}$ in a continuous strip on slice $\mathrm{OM}+4$. Additional areas included a "fronto-temporal bridge" (FTCB), representing an island of cortical tissue between the frontal and temporal areas on slice $\mathrm{OM}+4$, a limbic strip representing the combined values of temporal and frontal regions of interest, and the basal ganglia, which were assessed directly from a visual display unit using a $2.6 \mathrm{~cm}^{2}$ ROI.
Statistical analysis of the data was using one way Anova following $\log$ transformation and the post hoc means test.

\section{Results}

The basic epidemiological information regarding the patients is shown in table 1 . There were no significant differences between the groups for age, IQ or seizure frequency in the month prior to the scan. The PSE ratings for the two psychotic groups were as follows: In the untreated group, four were nuclear schizophrenia (NS), one psychotic depression (PD), and one patient did not have a PSE but had clinical symptoms of schizophrenia, and a past history of first rank nuclear symptoms. In the treated group two had a categorisation NS, two depressive psychosis (PD), one paranoid psychosis (DP), and one patient was improved and not rated as psychotic.

Absolute values for the rCMRO2, rCBF and rOER for the left and right sides of the brain are shown in table 2. One way Anova of all four groups revealed statistical differences in the following areas: The rCMRO2 was significantly greater in the non-epileptic sample compared with one of theo epileptic groups in the left temporal regions, the lefe्? basal ganglia, and the right anterior temporal reg® ion. The rCBF was significantly greater in the nong epileptic sample in the left temporal anterior andtposterior region, and the right mid and posteriof temporal region, the right FTCB, the right basaf ganglia and the right limbic strip. The non epileptic sample had a significantly lower rOER compared to the non-psychotic epileptics in the left FTCB, the right temporal anterior region, the right FTCB and the right limbic strip.

Analysis of the three epileptic groups revealed significant differences between the epileptic nonpsychotic and the epileptic psychotic group, but in addition, differences between the epileptic psychotic untreated, and the epileptic psychotic treated groups. With regard to the former, the rOER was significantly lower in the epileptic psychotic sample in all areas examined, with the exception of the left and right occipital areas, and the right temporal medial area. In the latter a trend $(p<0.1)$ was observed.

Table 1 Groups under investigation

\begin{tabular}{llll}
\hline & $\begin{array}{l}\text { Mean age } \\
(y r)\end{array}$ & Mean IQ & $\begin{array}{l}\text { Mean seizures } \\
\text { per } \text { month }\end{array}$ \\
\hline $\begin{array}{llll}\text { Control, non epileptic } \\
\text { Epileptic, non psychotic }\end{array}$ & $\begin{array}{l}37 \cdot 8 \\
34 \cdot 0\end{array}$ & -98 & - \\
$\begin{array}{l}\text { Epileptic, psychotic } \\
\text { Epileptic, psychotic, }\end{array}$ & $38 \cdot 2$ & 97 & $3 \cdot 9$ \\
on neuroleptics & 42.3 & 96 & 1.4 \\
\hline
\end{tabular}

(*1 patient had 30) 
Table 2 Showing values for $r \mathrm{CMRO}_{2}, \mathrm{rCBF}$ and $r \mathrm{OER}$ in the regions assessed in this study. Significance values are from post-hoc means tests on data analysed from the three epileptic samples only. Significance differences between non-epileptic volunteers and epileptic samples not given in the table.

\begin{tabular}{|c|c|c|c|c|c|c|c|}
\hline & & \multicolumn{6}{|c|}{ Psychotic treated and untreated } \\
\hline & & \multicolumn{3}{|l|}{ Left } & \multicolumn{3}{|l|}{ Right } \\
\hline & & $\mathrm{rCMRO}_{2}$ & rCBF & rOER & $\mathrm{rCMRO}_{2}$ & rCBF & rOER \\
\hline \multirow[t]{4}{*}{ Frontal } & $\mathrm{C}$ & $3 \cdot 6 \pm 0.2$ & $47 \cdot 2 \pm 10 \cdot 5$ & $0.43 \pm 0.10$ & $3.6 \pm 0.4$ & $46 \cdot 5 \pm 10 \cdot 2$ & $0.44 \pm 0.11$ \\
\hline & $\mathrm{E}$ & $3 \cdot 3 \pm 0.8$ & $36 \cdot 1 \pm 9.7$ & $0.52 \pm 0.051$ & $3 \cdot 2 \pm 0.8$ & $35.8 \pm 10.7$ & $0.52 \pm 0.04$ \\
\hline & EP & $3.2 \pm 0.6$ & $42 \cdot 3 \pm 4 \cdot 3$ & $0.41 \pm 0.04] \dagger$ & $2.8 \pm 0.4$ & $36.9 \pm 5.9$ & $0.42 \pm 0.05$ \\
\hline & EPT & $2.9 \pm 0.6$ & $32 \cdot 7 \pm 7 \cdot 1$ & $0.46 \pm 0.06$ & $2 \cdot 7 \pm 0.51$ & $31 \cdot 5 \pm 8 \cdot 8$ & $0.46 \pm 0.07$ \\
\hline \multirow[t]{4}{*}{ Temporal (A) } & C & $4.9 \pm 0.9$ & $64 \cdot 7 \pm 19 \cdot 0$ & $0.45 \pm 0.12$ & $4.5 \pm 0.5$ & $52 \cdot 4 \pm 20 \cdot 3$ & $0.43 \pm 0.10$ \\
\hline & $\mathbf{E}$ & $3.6 \pm 1.4$ & $42 \cdot 8 \pm 19 \cdot 0$ & $0.50 \pm 0.05]$ & $3 \cdot 9 \pm 1 \cdot 3$ & $40.8 \pm 15.2$ & $0.56 \pm 0.03]$ \\
\hline & EP & $3.2 \pm 0.5$ & $43.9 \pm 6.4$ & $0.40 \pm 0.04]$ & $3.6 \pm 0.3$ & $49.1 \pm 5.8$ & $0.41 \pm 0.05]$ \\
\hline & EPT & $3.0 \pm 0.7$ & $35.8 \pm 8.0$ & $0.44 \pm 0.05$ & $3.1 \pm 0.6$ & $36.4 \pm 7.7$ & $0.43 \pm 0.05$ \\
\hline \multirow[t]{4}{*}{ Temporal (M) } & C & $5 \cdot 2 \pm 0.5$ & $56.4 \pm 20.3$ & $0.44 \pm 0.13$ & $4.5 \pm 1.0$ & $58.9 \pm 18.2$ & $0.46 \pm 0.13$ \\
\hline & $\mathbf{E}$ & $3.7 \pm 1.2$ & $41 \cdot 7 \pm 15 \cdot 2$ & $0.52 \pm 0.06]$ & $3.7 \pm 0.8$ & $40.5 \pm 9.3$ & $0.54 \pm 0.06$ \\
\hline & EP & $3.2 \pm 0.5$ & $44.2 \pm 3.7$ & $0.40 \pm 0.05]$ & $3.8 \pm 0.5$ & * $[49.9 \pm 5.3$ & $0.41 \pm 0.05$ \\
\hline & EPT & $3 \cdot 2 \pm 0.8$ & $37.0 \pm 9.8$ & $0.45 \pm 0.05$ & $3.4 \pm 0.8$ & ${ }^{*}[38.4 \pm 7.5$ & $0.42 \pm 0.11$ \\
\hline \multirow[t]{4}{*}{ Temporal (P) } & C & $4.5 \pm 0.5$ & $56.3 \pm 13.7$ & $0.46 \pm 0.11$ & $4 \cdot 3 \pm 0 \cdot 10$ & $53.9 \pm 7.4$ & $0.43 \pm 0.12$ \\
\hline & E & $3.4 \pm 0.8$ & $37 \cdot 1 \pm 12 \cdot 1$ & $0.52 \pm 0.04$ & $3.3 \pm 0.5$ & $34.5 \pm 7.7$ & $0.56 \pm 0.08$ \\
\hline & EP & $2.9 \pm 0.5$ & $38.5 \pm 4.2$ & {$[0.41 \pm 0.06]$} & $3.5 \pm 0.3$ & $45.7 \pm 7.1$ & $0.42 \pm 0.06$ \\
\hline & EPT & $2.9 \pm 0.5$ & $34.3 \pm 8.7$ & $*[0.48 \pm 0.05$ & $3.4 \pm 0.9$ & $37 \cdot 8 \pm 11 \cdot 1$ & $0.48 \pm 0.06$ \\
\hline \multirow[t]{4}{*}{ Occipital } & C & $4 \cdot 2 \pm 0.6$ & $48.0 \pm 16.7$ & $0.53 \pm 0.15$ & $4.4 \pm 0.4$ & $47 \cdot 5 \pm 14 \cdot 1$ & $0.54 \pm 0.13$ \\
\hline & $\mathbf{E}$ & $3.6 \pm 1.0$ & $39.0 \pm 14.7$ & $0.59 \pm 0.06$ & $4 \cdot 0 \pm 1 \cdot 1$ & $42 \cdot 1 \pm 14 \cdot 4$ & $0.55 \pm 0.03$ \\
\hline & EP & $3.4 \pm 0.5$ & $38.7 \pm 8.1$ & $0.49 \pm 0.03$ & $3.7 \pm 0.4$ & $43.4 \pm 6.7$ & $0.49 \pm 0.03$ \\
\hline & EPT & $3.1 \pm 0.5$ & $29.2 \pm 6.0$ & $0.59 \pm 0.13$ & $3.4 \pm 0.6$ & $33.6 \pm 7.9$ & $0.59 \pm 0.13$ \\
\hline \multirow[t]{4}{*}{ FTCB } & $\mathrm{C}$ & $3.4 \pm 0.3$ & $42.9 \pm 8.4$ & $0.43 \pm 0.01$ & $3.4 \pm 0.3$ & $44 \cdot 1 \pm$ & $0.44 \pm 0.10$ \\
\hline & E & $3.1 \pm 0.7$ & $34 \cdot 2 \pm 8 \cdot 7$ & $0.53 \pm 0.04$ & $3.1 \pm 0.8$ & $31.7 \pm$ & $0.55 \pm 0.06$ \\
\hline & EP & $2.5 \pm 0.4$ & $35 \cdot 3 \pm 1.9$ & $+[0.39 \pm 0.05]$ & $2.8 \pm 0.3$ & [ $38.9 \pm$ & $+[0.40 \pm 0.04]$ \\
\hline & EPT & $2.5 \pm 0.5$ & $28.2 \pm 6.2$ & $t\left[\begin{array}{l}0.47 \pm 0.06 \\
0\end{array}\right.$ & $2.5 \pm 0.3$ & * $\left[\begin{array}{l}29.0 \pm 5.0 \\
0.0\end{array}\right.$ & $\mp[0.46 \pm 0.05$ \\
\hline \multirow[t]{4}{*}{ Limbic Strip } & $\mathrm{C}$ & $3 \cdot 5 \pm 1 \cdot 1$ & $52.6 \pm 11.4$ & $0.44 \pm 0.10$ & $3.9 \pm 0.3$ & $50.7 \pm$ & $0.44 \pm 0.11$ \\
\hline & E & $3.3 \pm 0.8$ & $37.1 \pm 11.9$ & $0.52 \pm 0.04]+$ & $3.3 \pm 0.8$ & $35.9 \pm$ & $0.54 \pm 0.047$ \\
\hline & EP & $2.9 \pm 0.5$ & $41.5 \pm 1.2$ & $\pm[0.38 \pm 0.05] \mp$ & $3.3 \pm 0.4$ & $42.4 \pm 4.4$ & $0.41 \pm 0.04$ \\
\hline & EPT & $2 \cdot 8 \pm 0.6$ & $32.9 \pm 6.9$ & $+[0.47 \pm 0.05$ & $2.9 \pm 0.6$ & $33.9 \pm 7.3$ & $0.46 \pm 0.06$ \\
\hline \multirow[t]{4}{*}{ Basal Ganglia } & $\mathrm{C}$ & $4.9 \pm 0.7$ & $61 \cdot 0 \pm 12 \cdot 5$ & $0.46 \pm 0.13$ & $4.6 \pm 0.8$ & $62 \cdot 6 \pm 13 \cdot 1$ & $0.45 \pm 0.14$ \\
\hline & E & $3.7 \pm 1.5$ & $45 \cdot 4 \pm 21 \cdot 0$ & $0.47 \pm 0.047$ & $3.7 \pm 1 \cdot 1$ & $44 \cdot 1 \pm 14 \cdot 1$ & $0.48 \pm 0.05$ \\
\hline & $\overline{E P}$ & $3.2 \pm 0.6$ & $49.3 \pm 5.1$ & {$[0.38 \pm 0.06] *$} & $3.5 \pm 0.5$ & $51.7 \pm 5.2$ & {$[0.40 \pm 0.04]$} \\
\hline & EPT & $3.5 \pm 0.7$ & $40.3 \pm 8.7$ & ${ }^{*}[0.49 \pm 0.09$ & $3.5 \pm 0.9$ & $38 \cdot 3 \pm$ & $*\left[\begin{array}{l}0.49 \pm 0.07 \\
0\end{array}\right.$ \\
\hline
\end{tabular}

$\mathrm{C}=$ Control: $\mathrm{E}=$ Epilepsy, non-psychotic: EP = Epileptic Psychotic on no neuroleptics: EPT = Epileptic psychotic on neuroleptics. ${ }^{*} p<0.05$

$+\mathrm{p}<0.01$

$\ddagger \mathrm{p}<0.001$

Table 3 Showing values of left-right side comparing the epileptic non-psychotic to the epileptic psychotic group

\begin{tabular}{|c|c|c|c|c|}
\hline & & $E P$ & Control & Significance \\
\hline Frontal & $\begin{array}{l}\mathrm{CMRO}_{2} \\
\mathrm{CBF} \\
\text { OER }\end{array}$ & $\begin{array}{l}+0.4 \\
+5.4 \\
0\end{array}$ & $\begin{array}{l}+0 \cdot 1 \\
+0 \cdot 3 \\
0\end{array}$ & $\begin{array}{l}0.10 \\
0.04\end{array}$ \\
\hline Temporal (A) & $\begin{array}{l}\text { CMRO } \\
\text { CBF } \\
\text { OER }\end{array}$ & $\begin{array}{l}-0.4 \\
-0.4 \\
-5.2 \\
-0.01\end{array}$ & $\begin{array}{l}-0.3 \\
-1.9 \\
-0.05\end{array}$ & \\
\hline Temporal (M) & $\begin{array}{l}\text { OER } \\
\text { CMRO } \\
\text { CBF } \\
\text { OER }\end{array}$ & $\begin{array}{l}-0.01 \\
-0.6 \\
-5.7 \\
-0.01\end{array}$ & $\begin{array}{l}-0.05 \\
0 \\
-1.1 \\
-0.03\end{array}$ & $\begin{array}{l}0.02 \\
0.05\end{array}$ \\
\hline Temporal (P) & $\begin{array}{l}\text { CMRO } \\
\text { CBF } \\
\text { OER }\end{array}$ & $\begin{array}{l}-0.6 \\
-7.2 \\
-0.01\end{array}$ & $\begin{array}{l}-0.03 \\
+2 \cdot 6 \\
-0.04\end{array}$ & $\begin{array}{l}0.06 \\
0.06\end{array}$ \\
\hline FTCB & $\begin{array}{l}\mathrm{CMRO}_{2} \\
\mathrm{CBF} \\
\mathrm{OER}\end{array}$ & $\begin{array}{l}-0.3 \\
-3.5 \\
-0.01\end{array}$ & $\begin{array}{c}0 \\
+2.4 \\
0.02\end{array}$ & 0.10 \\
\hline Occipital & $\begin{array}{l}\text { CMRO } \\
\text { CBF } \\
\text { OER }\end{array}$ & $\begin{array}{l}-0 \cdot 3 \\
-4 \cdot 7 \\
0\end{array}$ & $\begin{array}{l}-0.4 \\
-3.0 \\
0\end{array}$ & \\
\hline Basal Ganglia & $\begin{array}{l}\text { CMRO } \\
\text { CBBF } \\
\text { OER }\end{array}$ & $\begin{array}{l}-0.2 \\
-2.5 \\
-0.02\end{array}$ & $\begin{array}{l}-0.0 \\
+1.3 \\
-0.01\end{array}$ & \\
\hline Limbic Strip & $\begin{array}{l}\mathrm{CMRO}_{2} \\
\mathrm{CBF} \\
\text { OER }\end{array}$ & $\begin{array}{l}-0.4 \\
-0.9 \\
-0.02\end{array}$ & $\begin{array}{l}\quad 0 \\
+1 \cdot 2 \\
+0.01\end{array}$ & 0.006 \\
\hline
\end{tabular}


An analysis of laterality differences was carried out by subtracting the values for the right hemisphere from those of the left hemisphere and comparing the resultant differences between the epileptic psychotic and the non-psychotic epileptic control group. The absolute values for the differences are shown in table 3 for the two epileptic samples. Significant differences are noted for several values. In the frontal area, the epileptic psychotic group have a significantly higher value for the rCBF than the non-psychotic group (that is a higher left frontal flow). In the temporal areas, the CMRO2 difference is significantly lower medially and posteriorly $(\mathrm{p}<$ $0.06)$, and the CBF posteriorly $(\mathrm{p}<0.06)$ in the psychotic sample, and the OER significantly higher in the temporal anterior zone. In addition the rCMRO2 in the limbic strip is significantly lower in the psychotic group. No significant laterality differenes emerged in the basal ganglia or the occipital zones.

When the psychotic non-treated, and the neuroleptic treated group were compared (table 1), the latter showed significantly higher values for the rOER in the left posterior temporal region, the left limbic strip, and both the left and right FTCB and basal ganglia. Significant laterality differences between the epileptic psychotic treated, and the epileptic non-psychotic groups were seen on one analysis, which was in the temporal anterior rOER.

In addition to the absolute values, it is of importance and interest to note the pattern of abnormality recorded. Thus for the $\mathrm{rCMRO} 2$ and the $\mathrm{rCBF}$, the non-epileptic volunteers have the highest values of all groups for all regions examined. With regard to the rCMRO2, the pattern of controls greater than epilepsy, greater than epilepsy psychotic, greater than epilepsy psychotic treated, occurs in 10 out of 16 areas examined, the main exceptions being in the left basal ganglia where the treated group have a higher CMRO2 than the non-treated group. With regard to the $\mathrm{rCBF}$, the pattern of control greater than epileptic psychotic, greater than epileptic non-psychotic, greater than epileptic treated groups, is seen in 14 out of 16 areas examined, the exceptions being in the left occipital and the right posterior temporal areas. For the rOER, the pattern epileptic non-psychotic greater than epileptic psychotic treated, greater than controls, greater than epileptic psychotic non-treated, is seen in 10 out of 16 areas examined, the main exceptions being in the occipital lobes and the basal ganglia, in which the epilepsy psychotic treated have the highest values.

\section{Discussion}

This is the first study of epileptic psychosis using the technique of positron emission tomography to examine regional differences in cerebral blood flow and oxygen metabolism between psychotic and non-psychotic controlled samples. The number of scans performed, and the number of patients available for study is necessarily limited and the conclusions reached are therefore only tentative. However, quantitative analysis of our scan data does reveal significant and interesting differences between the groups. First, with regard to differences between the non-epileptic volunteer sample and the three epileptic groups, we confirm that the results of this study are similar to those we have presented elsewhere. ${ }^{10}$ Generally the control sample has higher values for $\mathrm{CMRO} 2$ and $\mathrm{CBF}$ than the epileptic groups, and the most significant differences are seen in the temporal cortices, particularly in the mid and posterior temporal zones. These data also note the higher values for the rOER in the epileptic sample, significant in some of the analyses, a finding we noted in the first study.

Analysis of the epileptic samples shows interesting differences between the groups. A consistent pattern appears to emerge, and while not significant in all zones, the consistency of the results does sug gest that the statistical values do not merely reflece chance associations. Comparing the patients with epilepsy and no psychosis to those with psychosis, iR should be noted that there is in many of the regions examined a lower value for the rOER in the psychon tic sample. This regional oxygen extraction fraction reflects the relationship between the $\mathrm{rCMRO} 2$ and the rCBF, and the significant differences in these data are consistent with the epileptic psychotic sample showing lower rCMRO2 and higher CBF in many of the regions analysed. The fact that the significant differences emerge mainly in the frontotemporal regions, and are not seen in the occipital region, may be of relevance, suggesting more involvement of limbic system related cortex in the pathology of temporal lobe epilepsy, supported by the highly significant differences for the limbic strip and the basal ganglia. We do not think that the differences between the psychotic and non-psychotic samples reflect age differences, as the groups were well matched in that regard, and in addition, changes of grey matter rCMRO2, are minimal with ageing. ${ }^{9}$ Neither is it likely to reflect partial volume effects, since the latter which may affect the rCMRO2 and rCBF will equalise out in the calculation of the rOER. In addition, the CT scans of the epileptic patients did not reveal any clear structural deficits, only two patients from the whole series showing minimal cerebral atrophy. Further, the epileptic control sample has three patients with right sided and two with left sided EEG abnormalities, in 
comparison with the psychotic sample which has three with right sided lesions and one with a left sided lesion. The other patients in the series had bilateral disturbances.

The finding of lower regional oxygen extraction fraction in the psychotic sample must be seen in the light of other groups who have examined patients with psychosis using similar techniques. The literature on cerebral blood flow and psychosis goes back many years to the original studies of Kety and coworkers $^{11}$ who, using the nitrous oxide technique, found normal values in chronic schizophrenics. Using more sophisticated methods of regional analysis and inhalation with either 85-Krypton or 133-Xenon, Ingvar and his group have suggested deviations of the rCBF distributions compared with normals. In particular the pattern of hypofrontality was noted, a finding replicated by others. ${ }^{13}$ Several groups have examined patients with schizophrenia using positron emission tomography, although the published literature refers mainly to fluorodeoxyglucose, as opposed to oxygen, as the metabolite of choice. Buchsbaum et al $^{14}$ have presented data on sixteen patients with schizophrenia, diagnosed by the DSM3 and the research diagnostic criteria of Spitzer and examined cortical values for glucose metabolism in comparison with normal controls. They confirmed the low frontal values in the psychotic sample, and in an extended analysis of their data, have looked for further regional differences. ${ }^{15}$ In schizophrenic patients, diminished fluorodeoxyglucose was noted in the left cortex in comparison with the right, and the values for the left anterior central grey matter tended to be lower in the schizophrenics compared to the normals. Our findings, therefore, of lower CMRO2, and in particular, lower extraction ratio in the epileptic psychotic patients when compared with the non-psychotic epileptic controls are in keeping with lower metabolic values found in some of these glucose studies in psychosis.

The only other study of psychosis using 150 and positron tomography is that recently reported by Sheppard et al..$^{20}$ They examined 12 schizophrenic patients and matched controls, all the patients being free from neuroleptic medication. Although the areas sampled in analysis were different from those reported here, the similarities and differences in the reported data should be commented on. Thus they also reported low rCMRO2 in the psychotic sample in the basal ganglia, although the rCBF in their analysis was also lower. They did not report their rOER data. Interestingly, they were unable to confirm the "hypofrontality hypothesis" widely discussed by others.

With regard to the laterality differences, our findings are in keeping with the now substantial lit- erature which emphasises left sided disturbances in patients with schizophrenia or schizophreniform disorders. Thus there is evidence from a variety of fields, whether it be neuropsychological, electrophysiological, ${ }^{16}$ radiological using CT scan densities, ${ }^{17}$ or clinical from, for example, head injury studies, ${ }^{18}$ or other series of patients with temporal lobe epilepsy. ${ }^{19}$ The provisional results of Buchsbaum et l $^{14}$ are mentioned above, but similar laterality differences are also being reported from other groups using positron tomography. ${ }^{21}$ The study of Sheppard et al also commented on laterality, and in some of their regional analyses right-left differences emerged. Thus on their $\mathrm{OM}+4$ slice there was greater right rCBF in the anterior region, and greater left $\mathrm{rCBF}$ in the posterior and mid-posterior segments. In the context of the CT scan studies reported by Toone $e \mathrm{al}^{8}$ in epileptic psychosis, the findings presented here are further evidence for functional, as opposed to structural changes being implicated in the pathogenesis of the epileptic psychosis.

Five of our six patients in the untreated psychotic group had a psychosis with nuclear first rank symptoms of schizophrenia, in four rated as NS with the Present State Examination. These findings should be seen in the light of our earlier work, ${ }^{\circ}$ in which a psychosis categorisation of NS was seen in patients with left sided temporal lobe disturbances as detected from surface EEG recordings.

In this study we have also examined differences between patients treated with neuroleptic medications and untreated ones. Although several authors hint that antipsychotic medicine has no relationship to cerebral blood flow, ${ }^{13}$ short term use of, for example, haloperidol, has been shown to lower cerebral blood flow and preliminary results suggest increases in CMR glucose. ${ }^{15}$ The pattern of our analysis suggests that the cerebral blood flow may be affected since in many regions it was lowest in the epileptic psychotic treated group, significant in two analyses. However, further data on individual patients collected both on and off these drugs needs to be collected before firm conclusions can be drawn. It is however of further interest that the laterality differences noted for the non-treated psychotic sample are no longer present in the psychotic sample, suggesting some regularisation of abnormal patterns within the brain in the psychotic patients on treatment, perhaps reflected in the significant increase in the rOER in several areas in the treated group, providing values for the rOER that are similar and non-significantly different from the epileptic non-psychotic and the non-epileptic controls. Thus, in the treated group the rOER is "preserved", perhaps reflecting some therapeutic action of the drugs. Since the differences are seen especially in 
fronto-temporal and basal ganglia regions, but occur widely in several other regions that are not known to contain high amounts of dopamine they cannot simply be interpreted as a consequence of local dopamine blockade. The fact that we detect significant differences means that results from groups that have used patients recently treated with neuroleptic drugs to assess regional cerebral blood flow and metabolism must be interpreted with caution, particularly in view of the fact that many of the changes reported here occur in the more anterior regions of the brain, precisely those that have been implicated as being abnormal in some way in the psychotic patients.

In summary, we have examined patients with epilepsy and psychosis, and noted differences between them and their non-psychotic epileptic controls in studies using positron emission tomography and oxygen 15 . When compared with volunteers, the epileptic patients generally show lower values for $\mathrm{rCMRO} 2$ and $\mathrm{rCBF}$ in a variety of cerebral structures, but these are mainly in the anterior portions of the brain, in limbic related structures. Psychotic epileptic patients show the lowest rCMRO2 values compared with their non-psychotic counterparts, a finding in keeping with the growing studies on cerebral glucose use in schizophrenia. Treatment with neuroleptic medication appears to lower the rCBF, mainly in basal ganglia and limbic system related structures, but has less of an effect on the rCMRO2, thus increasing the rOER, tending to produce values comparable with control patients. Laterality differences demonstrated in the nonneuroleptic treated group, do not appear to be present in the treated sample, suggesting that one of the mechanisms whereby anti-psychotic medication may exert its effect is through a more generalised homogenisation of aberrant cerebral dysfunction, rather than a more direct action at localised sites within the brain, such as the region of the basal ganglia.

\section{References}

' Pond DA. Psychiatric aspects of epilepsy. Journal of the Indian Medical Profession 1957;3:1441-51.

${ }^{2}$ Hill D. Psychiatric disorders of epilepsy. Med Press. 1953;229:473-5.

${ }^{3}$ Slater E, Beard AW. The schizophrenia-like psychoses of epilepsy. Br J Psychiatry 1963;109:95-150.

${ }^{4}$ Perez MM, Trimble MR. Epileptic psychosisdiagnostic comparison with process schizophrenia. $\mathrm{Br}$
J Psychiatry 1980;137:245-9.

${ }^{5}$ Flor-Henry P. Psychosis and temporal lobe epilepsy. Epilepsia. 1969;10:363-95.

- Trimble MR, Perez MM. The phenomenology of the chronic psychoses of epilepsy. In: Koella WP, Trimble MR. (eds.) Temporal lobe epilepsy, Mania, Schizophrenia and the Limbic System. Basle: Karger, 1982:98-105.

${ }^{7}$ Kristensen O, Sindrup EH. Psychomotor epilepsy and psychosis. Acta Neurol Scand 1978;57:361-70.

${ }^{8}$ Toone BK, Dawson J, Driver MV. Psychoses of epilepsy. A radiological evaluation. $B r J$ Psychiatry 1982;140:244-8.

${ }^{9}$ Frackowiak RS, Lenzi GL, Jones T, Heather JD. Quantitative measurement of regional cerebral blood flow and oxygen metabolism in man using 15,O and positron emission tomography. $J$ Comput Assist Tomogr 1980;4:727-36.

${ }^{10}$ Bernardi S, Trimble MR, Frackowiak RJS, Wise RJS, Jones T. An interictal study of partial epilepsy using positron emission tomography and the oxygen-15 inhalation technique. J Neurol Neurosurg Psychiatry 1983;46:473-7.

$"$ Kety SS, Woodford RB, Hormel MH, et al. Cerebral blood flow and metabolism in schizophrenia. Am J Psychiatry 1948; 104:765-70.

12 Ingvar DH, Franzen G. Abnormalities of cerebral blood flow distribution in patients with chronic schizo phrenia. Acta Psychiatr Scand 1974;50:425-62.

${ }^{13}$ Ariel RN, Golden CJ, Berg RA, et al. Regional cerebrå blood flow in schizophrenics. Arc Gen Psychiatre 1983;40:258-63.

${ }^{14}$ Buchsbaum MS, Ingvar DH, Kessler R, et al.Cerebrah glucography with positron tomography. Arc Gerg Psychiatry 1982;39:251-9.

${ }^{15}$ Delisi LE, Buchsbaum MS, Holcomb HH, et al. Lack oo correlation between hypofrontality in positron or emission tomography and clinical symptoms of schizophrenia. 1984. In press.

${ }^{16}$ Gruzelier JH. Cerebral laterality and psychopathology Fact or fiction. Psychol Med 1981;11:219-27.

17 Golden CJ, Graber B, Coffman J, Berg RA, Newlin DB, Bloch S. Structural deficits in Schizophrenia. Arch Gen Psychiatry 1981;38:1014-7.

${ }_{18}$ Hillbom E. After effects of brain injuries. Acta Psychiat Neurol Scand 1960;35. Supplement 142:1-195.

19 Trimble MR, Perez MM. Epileptic Psychosis-an evaluation of PSE profiles. Br J Psychiatry 1984. In press.

${ }^{20}$ Sheppard G, Manchanda R, Gruzelier J, Hirsch SR, Wise $R$, Frackowiak R, Jones T. 150 positron emission tomographic scanning in predominantly never treated acute schizophrenic patients. Lancet 1983;2: 1448-52.

${ }^{21}$ Brodie JD, Christmans DR, Corona JF, et al. Patterns of metabolic activity in the treatment of schizophrenia. Ann Neurol (suppl) 1984;S166-9. 